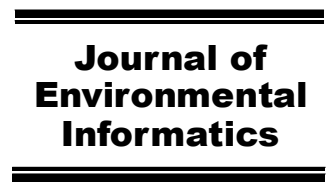

www.iseis.org/jei

\title{
A Hesitant Heterogeneous Approach for Environmental Impact Significance Assessment
}

\author{
Y. Zulueta ${ }^{1}$, R.M. Rodríguez ${ }^{2}$, R. Bello ${ }^{3}$, and L. Martínez ${ }^{4 *}$ \\ ${ }^{1}$ Faculty of Computational Technologies, University of Informatics Science, San Antonio Road, Km. 2 1/2, 19370, Havana, Cuba \\ ${ }^{2}$ Department of Computer Science and A.I., University of Granada, Periodista Daniel Saucedo Aranda, s/n 18014, Granada, Spain \\ ${ }^{3}$ Department of Computer Sciences, Faculty of Mathematics, Physics and Computer Sciences, Central University of Las Villas, \\ Camajuani Road km 5, 5, 54830, Santa Clara, Cuba \\ ${ }^{4}$ Department of Computer Science, University of Jaén, Campus Las Lagunillas, s/n 23071, Jaén, Spain
}

Received 20 April 2014; revised 1 October 2015; accepted 6 October 2015; published online 1 June 2017

\begin{abstract}
Projects and industrial activities developed by human beings generally affect their surroundings. For this reason, the efficacy of Environmental Impact Significance Assessment (EISA) method is increasingly demanded. There are multiple criteria involved in EISA problems that interact each other and may have either quantitative or qualitative nature. Classical approaches for EISA are not efficient in managing either uncertainty or different types of information, and the results obtained are numerical values difficult to interpret. The complexity of such problems and the uncertain information involved imply that experts sometimes hesitate among several values to express their assessments over criteria and they do not want to provide just one value, because it cannot reflect their hesitation. This brings about incomplete data in the experts' assessments. In order to deal with such situations, the concepts of hesitant fuzzy sets and hesitant fuzzy linguistic term sets have recently been introduced in quantitative and qualitative contexts respectively. Therefore, the aim of this paper is to define an EISA approach that allows managing heterogeneous information, including hesitant information. This approach provides a flexible evaluation framework in which experts can express their assessments, using different information domains that are unified in a linguistic domain by the 2-tuple linguistic model. It also obtains accurate results, which are easy to understand and interpret.
\end{abstract}

Keywords: Environmental Impact Significance Assessment, multicriteria decision making, heterogeneous information, hesitant information

\section{Introduction}

Projects and activities developed by human beings ineluctably cause positive or negative changes over the environment. Therefore, project approval decision making implies complex interdisciplinary processes to optimize resources in a sustainable way. An environmental impact assessment is a systematic process of determining and managing the potential impacts of proposed or existing human actions (projects, plans, programs, legislations, activities) and their alternatives on the environment (Lawrence, 2013).

Impact assessments have been used for quantifying impacts, either by using indicators to obtain the difference of environmental quality between situations "with project" and "without project" (a quantitative assessment based on magnitude), or according to the experts' judgements, commonly expressed in ordinal scales (a qualitative assessment based on significance) (Blanco et al., 2009; Conesa, 1997). Our interest is focused on the latter perspective, i.e., the Environmental Impact

\footnotetext{
* Corresponding author. Tel.: +34 953 211902; fax: +34 953212472.

E-mail address: martin@ujaen.es (L. Martínez).

ISSN: 1726-2135 print/1684-8799 online

(C) 2017 ISEIS All rights reserved. doi: 10.3808/jei.201700358
}

Significance Assessment (EISA) which is the process for determining the importance of the project's impacts on the affected environmental factors, considering subjective judgements provided in a qualitative or quantitative way.

There are two main problems related to EISA: (i) the selection of the best project from a set of alternatives, and (ii) the evaluation of environmental impacts of a single project. Both problems have a multi-criteria character since they are undertaken considering different interacting elements, and it is impossible to reduce these problems to one single criterion (Cloquell et al., 2007).

A Multi-Criteria Decision Making (MCDM) problem consists of selecting the best alternative from a set of possible alternatives according to a set of criteria (Ishizaka and Nemery, 2013; Pedrycz et al., 2011). In recent decades the interest in the application of MCDM methods in EISA has been renewed, since it produces transparent environmental impact assessment results and allows the consolidation of the interdisciplinary information into a unified decision making framework (Bojórquez -Tapia et al., 2005; Shepard, 2005).

An EISA problem can be intuitively modeled as a MCDM problem in which a project is evaluated through the impacts caused by the effect of its interactions with the surrounding environmental factors, and such impacts are assessed by one or more experts considering multiple criteria. It usually man- 
ages different features: first, large amounts of data that might be of poor quality because of uncertainty, measurement errors and even absence of such data; second, different spatial and temporal scales of impacts; and third, the concurrence of teams from several disciplines or areas of knowledge (Vrana and Aly, 2011; Onar, et al., 2014).

A key issue in EISA is to maximize the accuracy of the assessments while the results are kept understandable for stakeholders (Ijas et al., 2010). Given the complexity in EISA problems and the vagueness of the information, the preliminary judgements and the recognition of non-professional knowledge have already led to an increasingly formal (explicit, structured, documented) incorporation of experts' assessments in EISA models (Krueger et al., 2012). It demands a broad and inclusive concept of expertise that includes professionals such as scientists, managers of technical agencies, government reviewers, experienced members of the public and local community groups or individuals, and so on. Environmental assessments are subjective expressions of societal, group, and individual values and opinions which are not objective or directly measurable (Shepard, 2005); therefore, EISA methods should effectively deal with such feelings, beliefs, and imprecise concepts (Ahmadi et al., 2015; Li et al., 2011).

In an EISA problem, there are many criteria involved and they can be different in nature, either qualitative or quantitative. Nevertheless, one of the main limitations in traditional EISA methods is concerned to the incapacity of handling suitably information of qualitative and quantitative nature, because they indistinctively model the information into a numerical scale. There is another limitation in classical EISA methods (Conesa, 1997; Pastakiaand Jensen, 1998) that consists in using precise numerical values to assess criteria, despite the inherent ambiguities and imprecisions of impact assessment data. Moreover, these methods provide numerical results difficult to interpret in an environmental framework.

The complexity of EISA problems not only implies the necessity of a heterogenous context of definition (Carrasco and Villar, 2012; Herrera et al., 2005; Li et al., 2010) in which different types of information can model knowledge, the expertise and the uncertainty related to the information, but also makes experts provide vague and imprecise information and hesitate about their assessments.

For instance, if an expert has to provide his/her assessment about the recoverability of an impact, he/she might use a numerical value, because it is possible to obtain a precise reconstruction time of the affected factor by human intervention. However, if an expert has to provide his/her assessment about the intensity of an environmental impact, it is much more difficult to provide precise numerical values because this criterion is qualitative in nature and it seems more suitable to use linguistic terms, such as "low", "medium", "high" that better model the qualitative nature and inherent subjectivity than a numerical value.

Sometimes, due to the lack of information and/or knowledge about the EISA problem, experts might hesitate among several values to elicit their assessments. In such cases, the use of just one value could not be enough to reflect their hesitation in a precise way, and it might occur that experts do not provide any value, thus causing incomplete data. In order to cope with the uncertainty provoked by hesitancy, in quantitative contexts, Torra introduced the notion of Hesitant Fuzzy Sets (HFS) (Torra, 2010) and in qualitative contexts, Rodríguez et al. presented the concept of Hesitant Fuzzy Linguistic Terms Set (HFLTS) (Rodríguez et al., 2012). For instance, if an expert hesitates in determining if the intensity of an impact is "low" or "medium", he/she could elicit that the intensity is "between low and medium".

The aim of this paper is to propose a new EISA method that attempts to overcome the limitations of the traditional EISA methods. This proposal is able to deal with a heterogeneous context in which different types of information, such as numerical, linguistic, interval-valued, HFS and HFLTS, can be used to assess the criteria defined in an EISA problem, according to the criteria nature and experts' hesitation. Moreover, the use of hesitant information allows to reflect the experts' hesitation in a proper way. The proposed model conducts the heterogeneous information in a linguistic domain by means of the 2-tuple linguistic model (Herrera and Martínez, 2000; Martínez and Herrera, 2012), which accomplishes the computing with words (CWW) processes in a symbolic and precise way, obtaining linguistic results that are easy to understand by experts involved in EISA problems.

The remainder of the paper is organized as follows. Section 2 reviews a classical method for EISA problems and the management of hesitant information. Section 3 extends the 2tuple based heterogenous approach by including hesitant information. Section 4 presents the novel hesitant heterogeneous approach for EISA. Section 5 shows an example to illustrate the usefulness of the proposed approach. Section 6 highlights the main advantages of the proposal, and some conclusions are pointed out in Section 7. Appendix contains some necessary concepts to easily understand the proposed approach.

\section{Preliminaries}

This section revises a general method for EISA and shows its limitations to solve EISA problems in complex and uncertain contexts. The need of dealing with hesitant situations in which experts hesitate among several values to express their opinions has driven to the introduction of the HFS and HFLTS in the proposed model, thus they will be revised too.

\subsection{Classical Method for EISA Problems}

As discussed earlier, the EISA can be naturally modeled as a MCDM problem considering the following elements:

- A set of environmental factors $F=\left\{f_{i} \mid i \in\{1, \ldots, m\}\right\}$ affected by different actions.

- A set of actions $A=\left\{a_{j} \mid j \in\{1, \ldots, n\}\right\}$ executed to accomplish the project.

- A set of impacts $I=\left\{I_{i j} \mid i \in\{1, \ldots, m\}, j \in\{1, \ldots, n\}\right\}$ caused by the interaction of factors and actions.

- A set of criteria $C=\left\{c_{r} \mid r \in\{1, \ldots, t\}\right\}$ characterizing these im- 
pacts.

- One or more experts $E=\left\{e_{p} \mid p \in\{1, \ldots, q\}\right\}$ providing information about each impact over the set of criteria.

Matrix-based methods (Bojórquez-Tapia et al., 1998; Conesa, 1997; Pastakia and Jensen, 1998), which have a MCDM character, are the most frequently used to solve EISA problems because they are simple, inexpensive, and quick to apply (Bojórquez-Tapia et al., 1998; Toro et al., 2013).

A general method for EISA was introduced by Conesa (Conesa, 1997) based on the Battelle-Columbus Laboratories' method (Dee et al., 1973). It is briefly revised below and later on some of its limitations are pointed out.

\subsubsection{The General Method for EISA}

This method accomplishes the following steps:

1. Constructing the EISA matrix: A double-entry matrix relates the set of factors and the set of actions, and their intersections represents the possible impacts.

2. Assessing criteria for impacts: Once the impacts are identified, they are evaluated according to the criteria and numerical scales (Morón et al., 2009; Conesa, 1997). In (Conesa, 1997), it was also defined the nature as the beneficial $(+)$ or harmful (-) nature of the interaction of an action over an environmental factor.

3. Computing significance of impacts: For each identified impact, the value of significance is computed by using the following mathematical expression: $Y_{i j}= \pm\left(3 I N_{i j}+2 E X_{i j}+M O_{i j}+\right.$ $\left.P E_{i j}+R V_{i j}+S Y_{i j}+A C_{i j}+E F_{i j}+P R_{i j}+R C_{i j}\right)$

The conventional definition of criteria and acronyms used in the expression can be consulted in (Morón et al., 2009; Conesa, 1997). The result, independently of the nature, is a numerical value in the interval $[13,100]$, which is classified as follow:

- Irrelevant or compatible, if $Y_{i j} \in[13,25]$,

- Moderate, if $Y_{i j} \in[25,50]$,

- Severe, if $Y_{i j} \in[50,75]$ and

- Critical, if $Y_{i j} \in[75,100]$.

4. Updating the EISA matrix: Significance values obtained in the previous step are used to update the cross-boxes with the corresponding $Y_{i j}$.

5. Obtaining qualitative assessment indicators: Throughout algebraic sums by columns and rows respectively, the significance of actions and factors is calculated as well as the total significance of the project:

- Total significance of impacts over each factor: $Y_{i}=\sum_{i} Y_{i j}$

- Total significance of impacts caused by each action: $Y_{j}=$ $\sum_{j} Y_{i j}$

- Total significance: $Y=\sum_{i} \sum_{j} Y_{i j}$

\subsubsection{Main Limitations}

Even though this EISA general method has been widely applied in the European Union, as well as in Central and South
America because of its versatility, simplicity, and cost-effectiveness (Toro et al., 2013), the analysis of its performance reveals some important weaknesses:

- Inconsistencies and inflexibility in the mathematical expression for the calculation of significance: On the one hand, criteria and their weights are fixed, although the environmental impact assessment process varies greatly. The effectiveness of an EISA is often highly dependent on how well the process fits the context (Lawrence, 2013).

- No uncertainty modeling: As the EISA of any project requires the evaluation of the likely positive and/or negative effects of very diverse actions on many and various environmental factors, the uncertainty and inaccuracy is inherent in the process. However, using solely numerical precise values for assessing criteria means such inherent uncertain nature of EISA is not considered.

- Incapacity for dealing with heterogeneous information: Regardless their qualitative or quantitative character, criteria are assessed by means of precise numerical values or linguistic descriptors, that are conducted into numerical values to compute the significance value. Therefore, it seems more appropriate to use different types of information such as, numerical, linguistic, interval-valued and so on, according to the nature of the criteria for their assessment (Herrera and Martínez, 2001).

- Incapacity for dealing with experts' hesitation: The classical model does not provide any mechanism for dealing with the hesitant information that often appears in these problems.

- Low interpretability of results: Outcomes are numerical values that are not always easy to interpret by experts involved in decision making based on EISA.

\subsection{Management of Hesitant Information}

An EISA problem is complex because deals with a large amount of information which might be vague and imprecise due to the measurements errors, missing data, etc. Its complexity, the lack of information or even the lack of experts' knowledge on it, implies that experts might hesitate among several values when they express their assessments about each impact and criterion. In these hesitant situations, the use of just one value is not enough to reflect their assessments and often experts do not provide any value because of their hesitation. In order to deal with this type of uncertainty provoked by hesitancy, in quantitative contexts, Torra introduced the concept of HFS (Torra, 2010) as an extension of fuzzy sets.

Definition 1. (Torra, 2010) Let $X$ be a reference set, a HFS on $\mathrm{X}$ is a function $\eta$ that returns a non-empty subset of values in $[0,1]$ :

$\eta: X \rightarrow \rho([0,1])$

Therefore, an HFS allows considering several possible values to fix the membership degree of an element to a fuzzy set. In the seminal paper (Torra, 2010), Torra proposed some basic operations for HFSs based on intervals and intuitionistic 
fuzzy sets. Some more operations can be found in Pei and Yi, (2015).

Similarly to the hesitant situations managed by means of HFS, in qualitative contexts, it may occur that experts hesitate among several linguistic terms to assess a linguistic variable. To deal with such situations Rodríguez et al. (Rodríguez et al., 2012) proposed the concept of HFLTS which is based on the fuzzy linguistic approach (Zadeh, 1975) and extends the concept of HFS to linguistic contexts.

Definition 2. (Rodríguez et al., 2012) Let $\mathrm{S}=\left\{\mathrm{s}_{0}, \ldots, \mathrm{s}_{\mathrm{g}}\right\}$ be a linguistic term set, a HFLTS $\mathrm{H}_{\mathrm{S}}$, is defined as an ordered finite subset of consecutive linguistic terms of S:

$H_{S}=\left\{s_{i}, s_{i+1}, \ldots, s_{j}\right\}$ such that $s_{k} \in S, k \in\{i, . ., j\}$

Some basic operations for HFLTS can be found in (Rodríguez et al. (2012).

In real-world problems experts commonly use linguistic expressions to provide their assessments and opinions instead of multiple linguistic terms. Therefore, to improve the elicitation of linguistic information, Rodríguez et al. (Rodríguez et al., 2013) proposed the use of context-free grammars to generate expressions close to human beings' reasoning. A contextfree grammar $G_{H}$, was defined to generate comparative linguistic expressions similar to the expressions used by experts in real-world decision making problems.

Definition 3. (Rodríguez et al., 2013) Let $\mathrm{G}_{\mathrm{H}}$ be a context-free grammar, and $S=\left\{s_{0}, \ldots, s_{g}\right\}$ be a linguistic term set. The elements of $G_{H}=\left(V_{N}, V_{T}, I, P\right)$ are defined as follows:

$\mathrm{V}_{\mathrm{N}}=\{\langle$ primary term $\rangle,\langle$ composite term $\rangle,\langle$ unary relation $\rangle,\langle$ binary relation $\rangle,\langle$ conjunction $\rangle$,

$V_{T}=\{$ greater than, lower than, at least, at most, between, and, $\left.\mathrm{S}_{0}, \ldots, \mathrm{s} \mathrm{g}\right\}$,

$I \in V_{N}$.

$P=\{I::=\langle$ primary term $\rangle \mid\langle$ composite term $\rangle$

$\langle$ composite term $\rangle::=\langle$ unary relation $\rangle\langle$ primary term $\rangle \mid$

$\langle$ binary relation $\rangle\langle$ primary term $\rangle\langle$ conjunction $\rangle\langle$ primary term $\rangle$

$\langle$ primary term $\rangle::=\mathrm{s}_{0}\left|\mathrm{~s}_{1}\right| \ldots \mid \mathrm{sg}_{\mathrm{g}}$

$\langle$ unary relation $::=$ greater than $|$ lower than |at least |at most

$\langle$ binary relation $\rangle::=$ between

$\langle$ conjunction> $::=$ and

The comparative linguistic expressions can be represented into a HFLTS applying a transformation function $E_{G_{H}}$ defined as follows:

Definition 4. (Rodríguez et al., 2013) Let $E_{G_{H}}$ be a function that transforms comparative linguistic expressions $S_{l l}$ obtained from a context-free grammar $G_{H}$, into HFLTS $H_{S}$, where $S$ is the linguistic term set used by $G_{H}$, and $S_{l l}$ is the set of linguistic expressions generated by $\mathrm{G}_{\mathrm{H}}$.

$E_{G_{H}}: S_{l l} \rightarrow H_{S}$

The linguistic expressions generated by the production rules will be transformed into HFLTS in different ways depen- ding on their meaning:

- $E_{G_{H}}\left(s_{i}\right)=\left\{s_{i} / s_{i} \in S\right\}$

- $E_{G_{H}}$ (lower than $\left.s_{i}\right)=s_{i} / s_{j} \in S$ and $s_{j}<s_{i}$

- $E_{G_{H}}$ (greater than $\left.s_{i}\right)=s_{i} / s_{j} \in S$ and $s_{j}>s_{i}$

- $E_{G_{H}}\left(\right.$ at least $\left.s_{i}\right)=s_{i} / s_{j} \in S$ and $s_{j} \geq s_{i}$

- $E_{G_{H}}\left(\right.$ at most $\left.s_{i}\right)=s_{i} / s_{j} \in S$ and $s_{j} \leq s_{i}$

- $E_{G_{H}}$ (between $\left.s_{i} \mathrm{y} s_{j}\right)=s_{k} / s_{k} \in S$ and $s_{i} \leq s_{k} \leq s_{j}$

\section{Extension of the Heterogenous Approach to Deal with Hesitant Information}

A common situation in problems with multiple criteria is the appearance of information of different nature that might be modeled with heterogeneous information such as numerical, linguistic, interval-valued and so on. There are different heterogeneous approaches (Carrasco and Villar, 2012; Herrera et al.,2005; Li et al., 2010) that manage these types of information. Nevertheless, none of them deals with hesitant information. Despite the concept of hesitant information has been recently introduced (Torra, 2010; Rodríguez et al., 2012), it has been successfully applied in different fields, such as decision making (Liao and Xu, 2013; Liu and Rodríguez, 2014; Wei et al., 2015), evaluation (Yu et al., 2013), clustering (Zhang and $\mathrm{Xu}, 2015)$, etc.

In this section we extend the heterogeneous approach (Herrera et al., 2005) revised in Appendix by including hesitant information (HFS and HFLTS). To do so, different transformation functions have been defined to conduct the hesitant information into a linguistic domain as depicts Figure 1. These functions are defined as follows.

\section{- Transforming HFS into a linguistic domain}

A HFS cannot be directly transformed into a 2-tuple linguistic value, therefore, the unification phase is divided into three steps:

1. Obtaining an interval: A numeric interval is built by using the lower and upper bounds defined for a HFS.

Definition 5. Let $h_{1}$ be a HFS, the interval of the $h_{1}$ is:

$h_{V_{I}}=\left[h_{1}^{-}, h_{1}^{+}\right]$

being $h_{1}^{-}=\min \{\gamma \mid \gamma \in h\}$ and $h_{1}^{+}=\max \{\gamma \mid \gamma \in h\}$.

2. Transforming into fuzzy sets: A transformation function $\tau_{V S_{T}}: V \rightarrow F\left(S_{T}\right)$ which transforms an interval $h_{V}$ into a fuzzy set in $S_{T}$ is applied (see Appendix, Definition 13).

3. Transforming into 2-tuple linguistic values: The fuzzy set $F\left(S_{T}\right)$, is converted into a 2-tuple linguistic value by using the transformation function $\chi(\cdot)$ (see Appendix, Definition 15).

\section{- Transforming HFLTS into a linguistic domain}

Due to a HFLTS is compounded of several linguistic ter$\mathrm{ms}$, to transform it into a linguistic domain, such linguistic ter- 


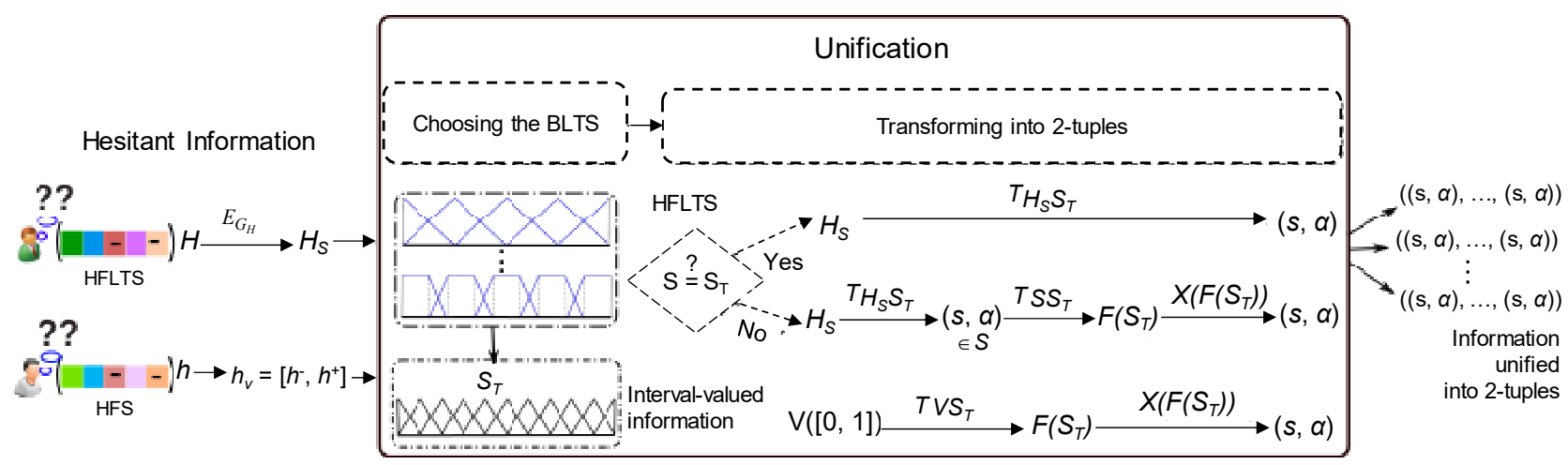

Figure 1. Scheme to manage hesitant information.

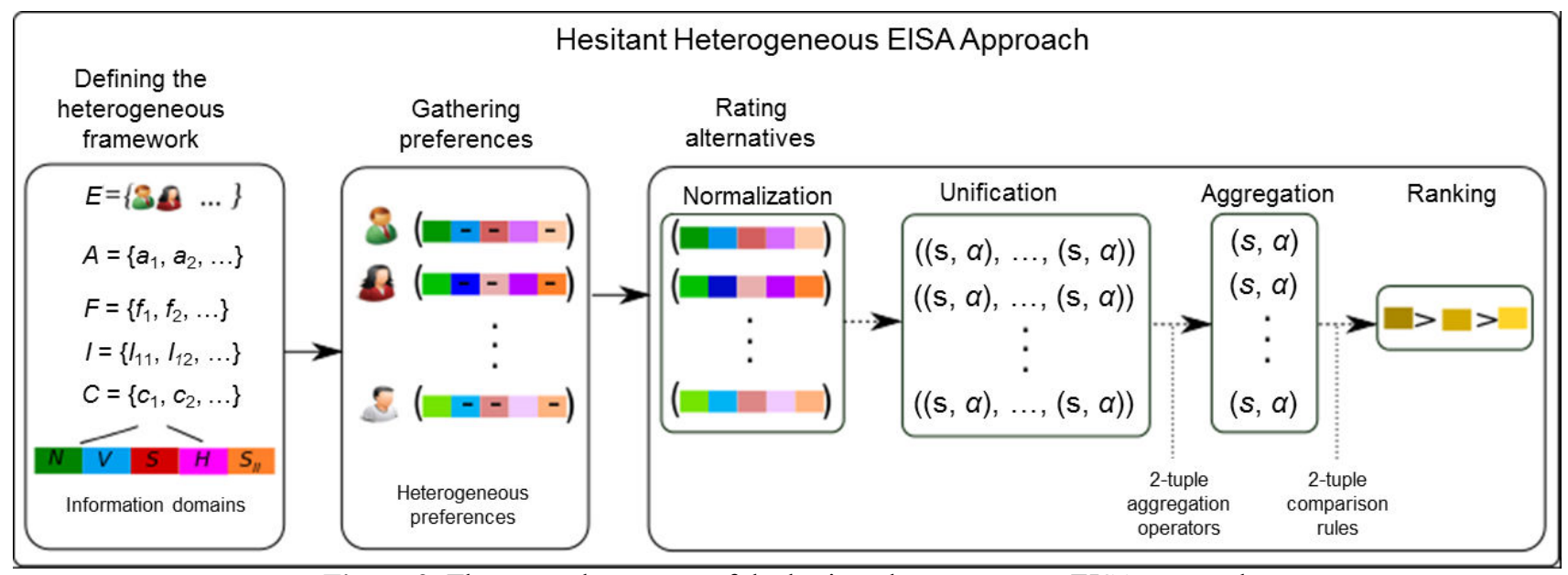

Figure 2. The general structure of the hesitant heterogeneous EISA approach.

ms are aggregated and the result is represented by means of a 2-tuple linguistic value.

In the unification process of HFLTS into 2-tuple linguistic values, there are two different situations to be considered: (i) the linguistic term set $S$, used by the grammar $G_{H}$ is selected as the BLTS, (ii) the linguistic term set $S$, is different to the BLTS, which means that $S_{T}$ is a linguistic term set with a granularity greater than $S$. Consequently the unification has to regard both options.

- If $S=S_{T}$ :

Definition 6. Let $H_{S_{I}}=\left\{s_{i}, \ldots, s_{j}\right\}$ be a HFLTS, the transformation function $\tau_{H_{S} S_{T}}: H_{S} \rightarrow S_{T} \times[-0.5,0.5)$ is defined as follows:

$\tau_{H_{S} S_{T}}\left(H_{S_{I}}\right)=\Delta\left(\sum_{k=i}^{j} w_{k} * k\right)$

where $w_{k} \in[0,1], \sum_{k=1}^{j} w_{k}=1$ and $k=\{i, \ldots, j\}$.

- If $S \neq S_{T}$ :

Once the 2-tuple linguistic value is obtained from the HFLTS, it is transformed into $S_{T}$ applying the transformation function for linguistic domain (see Appendix Definition14), that means that the 2-tuple linguistic value on $S$ will be transferred into a fuzzy set in $S_{T}$. Afterwards, the result is transformed into 2-tuple on $S_{T}$ by using the transformation function $\chi(\cdot)$.

\section{A Hesitant Heterogeneous Approach for EISA}

Here it is presented a novel hesitant heterogeneous approach for EISA which is able to manage numerical, linguistic, interval-valued, HFS and HFLTS domains in the assessment process according to the criteria nature and the experts' hesitation. It provides linguistic results accurate and easy to understand by experts involved in the EISA problem. In order to tackle the difficulty of dealing with this hesitant heterogeneous context in an EISA problem in a rational and well-organized manner, the proposed approach follows the classical decision analysis scheme (Clemen, 1996) which is divided into three main phases: (i) Defining the heterogeneous framework, (ii) Gathering preferences and (iii) Rating alternatives. Figure 2 shows the general structure of the approach.

As the criteria proposed by different authors for impact assessments, differ in number as in character, a suitable EISA evaluation framework enables the gathering of such heterogeneous information depending on the criteria nature. The first phase specifies the structure and representation of the input data including the information domains in which the experts will provide their preferences about impacts considering dif- 
ferent criteria. Such preferences are collected in the second phase. The third phase accomplishes the CWW processes to obtain linguistic significance values easy to interpret (Martínez et al., 2010).

To do so, the heterogeneous information is conducted into a common 2-tuple linguistic domain by using the transformation functions introduced in Section 3 and Appendix. The linguistic information is then aggregated in a multiple-step process to obtain the significance values which are compared to obtain final ranking of impacts, factors and actions. All phases are described in further detail in the following subsections.

\subsection{Defining the Heterogeneous Framework}

In this phase the elements of the EISA MCDM problem are defined according to Section 2.1. Additionally, let $\mathrm{W}=$ $\left(w_{r} \mid r \in\{1, \ldots, t\}\right), w_{r} \in[0,1]$ with $\sum_{r=1}^{t} w_{r}=1$ be the weighting vector for the criteria, and $U=\left\{u_{i j} \mid i \in\{1, \ldots, m\}, j \in\{1, \ldots, n\}\right\}$, $u_{i j} \in\{-1,1\}$ be the set for representing the nature of impacts, where -1 and 1 stand for the negative and positive impacts respectively.

Since criteria represent different dimensions of the impacts, they may conflict with each other (Triantaphyllou, 2000) originating the division of $C$ into two subsets: $C^{l}$ with benefit criteria and $C^{2}$ with cost criteria. It means that for the benefit criteria, the more the better, and for the cost criteria, the less the better. Furthermore $C=C^{l} \cup C^{2}$ and $C^{l} \cap C^{2}=\varnothing$ where $\varnothing$ is an empty set.

The preference provided by expert $e_{p} \in E$ about the impact of action $a_{j} \in A$ over factor $f_{i} \in F$ according to the criteria $c_{r} \in C$ is represented by $x_{i j}^{r p}$.

Criteria could be assessed using the following information domains, $O=\left\{N, V, S, H, S_{l l}\right\}$ :

- Numerical values $(N): x_{i j}^{r p}=v_{i j}^{r p} \in[0,1]$.

- Interval values (V): $x_{i j}^{r p}=V([0,1])=\left[a_{i j}^{r p}, b_{i j}^{r p}\right]$ with $a_{i j}^{r p}, b_{i j}^{r p} \in$ $[0,1]$ and $a_{i j}^{r p} \leq b_{i j}^{r p}$.

- Linguistic values (S): $x_{i j}^{r p}=s_{i j}^{r p} \in S=\left\{s_{0}, \ldots, s_{g}\right\}$ being $g+1$ the cardinality of the linguistic term set $S$.

- $\operatorname{HFS}(\mathrm{H}): x_{i j}^{r p}=h_{i j}^{r p} \in \rho([0,1])$.

- Comparative linguistic expressions $S_{l l}: x_{i j}^{r p}=l l_{i j}^{r p}$ generated by using context-free grammar $G_{H}$ revised in Section 2.2.

\subsection{Gathering Preferences}

Once the heterogeneous framework has been defined, each expert provides her/his preferences about impacts $I_{i j}$ by means of assessment vectors: $X_{i j}^{p}=\left(x_{i j}^{l p}, \ldots, x_{i j}^{r p}\right)$.

\subsection{Rating Alternatives}

Rating alternatives is critical in the resolution process, because in this phase the heterogeneous preferences are synthesized into full-valued significance assessments. Therefore, the four steps presented in Figure 2 are carried out. (i) The heterogeneous information is normalized to eliminate cost/benefit criteria conflicts. (ii) The information is conducted into a unique linguistic domain to facilitate the aggregation of preferen- ces. (iii) The preferences are aggregated to obtain linguistic significance values for impacts, factors and actions; as well as an interpretable full-value global significance of the project. (iv) Finally, a ranking of impacts, factors and actions is obtained.

\subsubsection{Normalization}

Due to the fact that the attributes are either cost or benefit ones, their values will be normalized as benefit criteria according to their type of information. Therefore, from a gathered cost preference $x_{i j}^{r p}$, its correspondent benefit preference, $x_{i j}^{r p}$, is expressed as:

- Numerical domain

$$
\bar{x}_{i j}^{r p}= \begin{cases}1-x_{i j}^{r p} & \text { if } c_{r} \in C^{2} \\ x_{i j}^{r p} & \text { otherwise }\end{cases}
$$

- Interval-valued domain

$$
\bar{x}_{i j}^{r p}= \begin{cases}{\left[1-b_{i j}^{r p}, 1-a_{i j}^{r p}\right]} & \text { if } c_{r} \in C^{2} \\ {\left[a_{i j}^{r p}, b_{i j}^{r p}\right]} & \text { otherwise }\end{cases}
$$

- Linguistic domain

$$
\bar{x}_{i j}^{r p}= \begin{cases}\operatorname{Neg}_{S}\left(s_{i j}^{r p}\right) & \text { if } c_{r} \in C^{2} \\ s_{i j}^{r p} & \text { otherwise }\end{cases}
$$

where $N e g$ is a linguistic negation operator such that $N e g\left(s_{i}\right)=$ $s_{g-i}$ (Herrera and Martínez, 2000).

- HFS domain

$$
x_{i j}^{r p}= \begin{cases}{\left[1-h_{i j}^{+r p}, 1-h_{i j}^{-r p}\right]} & \text { if } c_{r} \in C^{2} \\ {\left[h_{i j}^{-r p}, h_{i j}^{+r p}\right]} & \text { otherwise }\end{cases}
$$

where $h^{+}=\max \{\gamma \mid \gamma \in h\}$ and $h^{-}=\min \{\gamma \mid \gamma \in h\}$.

- Comparative linguistic expressions domain

$\bar{x}_{i j}^{r p}= \begin{cases}\operatorname{Neg}_{H_{S}}\left(E_{G_{H}}\left(l l_{i j}^{r p}\right)\right. & \text { if } c_{r} \in C^{2} \\ E_{G_{H}}\left(l l_{i j}^{r p}\right) & \text { otherwise }\end{cases}$

where $N e g$ is a linguistic negation operator over an $H_{S}$ such that $N \operatorname{Neg}_{H_{S}}\left(H_{S}\right)=N \operatorname{Neg}_{H_{S}}\left(\left\{s_{i}, s_{i+1}, \ldots, s_{j}\right\}\right)=\{g-j, g-(j-1), \ldots, g-i\}$.

\subsubsection{Unification into a Linguistic Domain}

Given that we assume a heterogeneous framework in the EISA problem, it is then necessary to make the information 


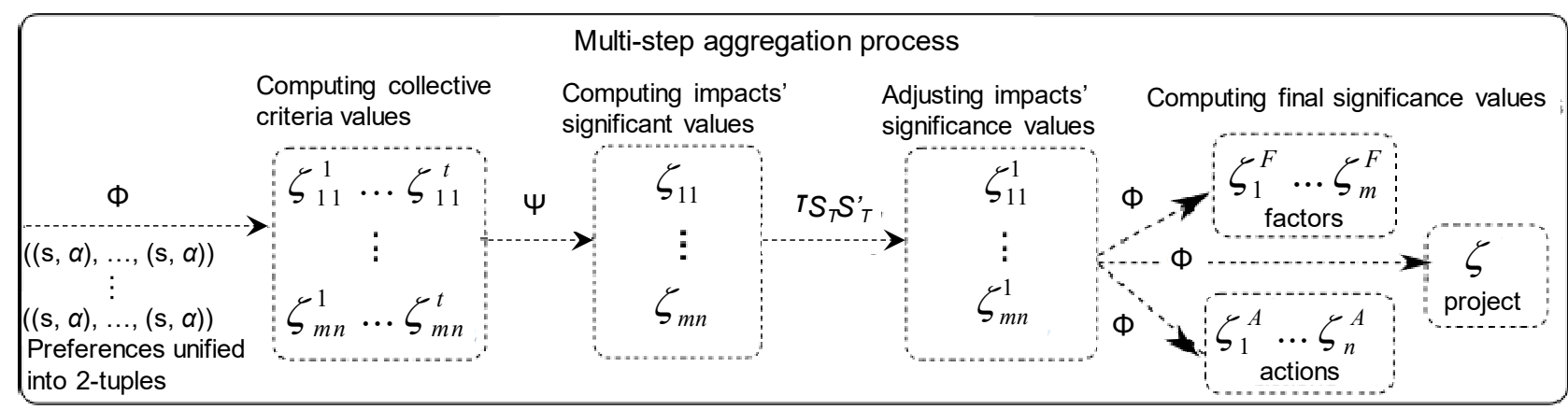

Figure 3. Schema of the multi-step aggregation process.

uniform before applying the multi-step aggregation process. Each normalized heterogeneous preference is conducted into a 2-tuple linguistic value:

$$
\hat{x}_{i j}^{r p}=\left\{\begin{array}{lll}
\chi\left(\tau_{N S_{T}}\left(\bar{x}_{i j}^{-p}\right)\right) & \text { if } & \bar{x}_{i j}^{r p} \in N \\
\chi\left(\tau_{V S_{T}}\left(\bar{x}_{i j}^{r p}\right)\right) & \text { if } & \bar{x}_{i j}^{r p} \in V \\
\chi\left(\tau_{S S_{T}}\left(\bar{x}_{i j}^{r p}\right)\right) & \text { if } & \bar{x}_{i j}^{r p} \in S \\
\chi\left(\tau_{H_{S} S_{T}}\left(\bar{x}_{i j}^{r p}\right)\right) & \text { if } & \bar{x}_{i j}^{r p} \in H_{S}
\end{array}\right.
$$

\subsubsection{Multi-step Aggregation Process}

In a MCDM problem, the aggregation process computes intermediate and global assessments on the set of alternatives. In the MCDM EISA problem, due to the multiple alternatives considered, that includes not only individual impacts but also the environmental factors, the actions and the project, it is necessary to perform the aggregation in a multi-step process to generate intermediate and global significance values.

In order to obtain interpretable significance results close to human beings' cognitive model and taking into account the linguistic modeling of the unified information, the proposed EISA approach carries out the CWW processes in a multi-step aggregation process which is supported by aggregation operators for 2-tuple linguistic values, such as the ones defined in (Herrera and Martínez, 2000; Liu et al., 2013; Merigó et al., 2010; Wan, 2013).

Once the preferences have been conducted into 2-tuple linguistic values, the multiple aggregation step is performed as follows (see Figure 3).

\section{Computing collective criteria values:}

The assessments of all experts about each criterion $c_{r}$, for each impact $I_{i j}$, is denoted as $\zeta_{i j}^{r}$, and it is computed with a 2-tuple aggregation operator, $\Phi$ :

$\zeta_{i j}^{r}=\Phi\left(\hat{x}_{i j}^{r l}, \ldots, \hat{x}_{i j}^{r q}\right)$

\section{Computing impacts' significance values:}

Using a 2-tuple weighted aggregation operator $\Psi$, with the weighting vector $W$, the significance value $\zeta_{i j}$ of each impact $I_{i j}$ is computed as:

$$
\zeta_{i j}=\Psi\left(\zeta_{i j}^{1}, \ldots, \zeta_{i j}^{t}\right)
$$

However, a linguistic value $\zeta_{i j}$, can not tell us if an impact will be positive or negative. It is necessary to adjust the significance according to the given nature to specify this fact, so-called adjusting significance.

\section{Adjusting impacts' significance values:}

In traditional numerical methods for EISA, positive numbers represent benefits caused by the project, whereas negative numbers indicate harm caused by it. From the original impact significance value, two new values (one positive and one negative) are obtained. To do so, it is used the 2-tuple based model to deal with multiple linguistic scales (see Appendix).

In order to solve our problem, a two-level LH should be constructed, with the BLTS, ST, at level 1 and a new Adjusted Linguistic Term Set (ALTS), generated as $l(t, n(t)) \rightarrow l(t+1$, $2 * n(t)-1)$, denoted as $S^{\prime}{ }_{T}$ following the linguistic hierarchy basic rules introduced in Appendix. Once we have the ALTS at level 2, to generate its semantic, a transformation function is defined:

Definition 7. Let $L H=U_{t} l(t, n(t))$ be a linguistic hierarchy whose term sets are

$$
\begin{array}{ll}
l(1, n(t)) & S_{T} \\
l\left(2,2^{*} n(t)-1\right) & S^{\prime}{ }_{T}
\end{array}
$$

and let us consider the 2-tuple linguistic model. The transformation function $\left.\tau_{S_{T} S_{T}^{\prime}}: l(1, n(t)) \rightarrow l(2,2 * n(t)-1)\right)$ of a 2-tuple linguistic value on $S_{T},(s k, \alpha)_{i j}$, into $S^{\prime}{ }_{T}$, according to the nature $u_{i j}$ of the impact $\zeta_{i j}$, is defined as:

$\tau_{S_{T} S_{T}^{\prime}}\left(\left(s_{k}, \alpha\right)_{i j}\right)=\left\{\begin{array}{l}\Delta^{-1}\left(\Delta\left(s_{k}, \alpha\right)_{i j}+\frac{2^{*} n(t)-1}{2}\right) \text { if } u_{i j}=1 \\ \Delta^{-1}\left(\frac{2 * n(t)-1}{2}-\Delta\left(s_{k}, \alpha\right)_{i j}\right) \text { if } u_{i j}=-1\end{array}\right.$

Finally all values $\zeta_{i j}$, are adjusted as:

$\zeta_{i j}^{\prime}=\tau_{S_{T} S_{T}^{\prime}}\left(\zeta_{i j}\right)$

As can be seen on Figure 4, the transformation function $\tau_{S_{T} S_{T}^{\prime}}($.$) , allows to outcome impacts' significance values on a$ 
new linguistic terms set $S_{T}^{\prime}=\left\{{S^{\prime}}_{0}, \ldots, S_{g^{\prime}}\right\}$, with $g^{\prime}=2 * g$ and its granularity $g^{\prime}+1$. On the ALTS, $S_{T}^{\prime}$, the term $s_{g^{\prime} / 2}^{\prime}$ represents the indifference, while the terms situated on its left side and on its right side represent the negative and the positive impacts respectively.

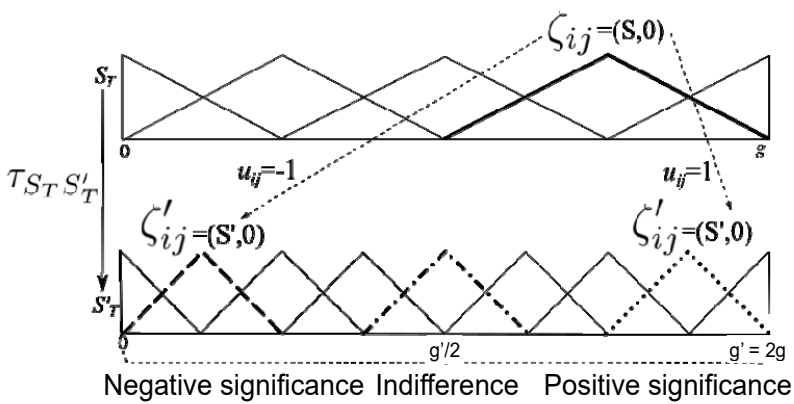

Figure 4. Transformation function for adjusting impact significance values.

\section{Computing final significance values:}

Using again a suitable problem-dependent 2-tuple aggregation operator $\Phi$, final indicators are generated: Factor's Significance $\left(\zeta_{i}^{F}\right)$, Action's Significance $\left(\zeta_{i}^{A}\right)$ and Global Significance $(\zeta)$ :

$\zeta_{i}^{F}=\Phi\left(\zeta_{i l}^{\prime}, \ldots, \zeta_{i n}^{\prime}\right)$

$\zeta_{j}^{A}=\Phi\left(\zeta_{1 j}^{\prime}, \ldots, \zeta_{m j}^{\prime}\right)$

$\zeta=\Phi\left(\zeta_{11}^{\prime}, \ldots, \zeta_{m n}^{\prime}\right)$

\subsubsection{Ranking Alternatives}

This phase transforms the global information about the alternatives into global rankings. Therefore, impacts, factors and actions are ordered according to their significance values. As they are expressed into 2-tuple linguistic values, the global rankings are obtained applying the comparison operation for 2-tuple (Herrera and Martínez, 2000) introduced in Appendix.

The larger the values, the better, therefore the more affected factors and the more aggressive actions, the significance values are lower.

\section{Illustrative Example}

In this section the functionality of the hesitant heterogenous approach for EISA is illustrated by means of the project for limestone mining in "El Cacao" deposit in Cuba (adapted from (Hernández et al., 2011)).

\subsection{Description of the Problem}

The implementation of a mining project includes a set of actions that affect the environment. These actions should be studied for each type of mineral and method of exploitation. The high demand of building materials in Cuba requires an increasing exploitation in the whole country which must be carried out in a sustainable way.

The development of new tools for the mining tasks together the environmental constraints force to use methods of exploitation that cause the least possible environmental impact, as well as reduce the production costs. In Cuba there are environmental regulations for all activities that provoke damage environmental. There is an environmental Law which establishes the requirement of minimizing the negative effects on the environment. The failure to fulfill of this law has sometimes led that the exploited areas are not properly rehabilitated after finishing the mining tasks. An example of this type of projects is the limestone mining in "El Cacao" deposit, that is located to the South of Jiguaní Municipality, Granma Province and it has been exploited for more than 40 years. In this place, limestone of high quality is extracted and during the implementation of the mining project have occurred ecological devastation.

Applying to this example the proposed approach for EISA, it is obtained a ranking of impacts, factors, actions and the overall impact of the project. Such results are accurate and linguistic easy to understand by human beings.

\subsection{Solving Process}

In order to solve the example, the resolution scheme depicted in Figure 2 is followed.

\subsubsection{Defining the Heterogeneous Framework}

This phase defines the EISA framework:

- Actions: land clearing $\left(a_{1}\right)$, raw material extracting $\left(a_{2}\right)$ and drilling and blasting $\left(a_{3}\right)$.

- Environmental factors: water $\left(f_{1}\right)$, flora $\left(f_{2}\right)$ and local infrastructures $\left(f_{3}\right)$. Although the selected actions interact with other environmental factors, such as soil, air, fauna, landscape and economy, we have selected water, flora and infrastructures, for the sake of simplicity and to better illustrate the different positive or negative nature of impacts caused by the project.

- The identified impacts are $I=\left\{I_{11}, I_{12}, I_{13}, I_{21}, I_{33}\right\}$.

- The nature of each impact is given by $U=\{-1,-1,-1,-1,1\}$.

- Information Domains:

○N: $[0,1]$.

$\circ \mathrm{H}: \rho([0,1])$

$\circ S_{l l}$ : Linguistic expressions generated by the $G_{H}$ introduced in Definition 3 using the linguistic term set of five terms $S^{5}$, shown in Figure 5.

- Impacts will be evaluated according to five criteria whose names and expression domains are:
o $c_{1}$, Intensity, $S_{l l}$
o $c_{2}$, Extension, $H$
o $c_{3}$, Moment, $N$
o $c_{4}$, Persistence, $S_{l l}$
o $c_{5}$, Reversibility, $S_{l l}$ 


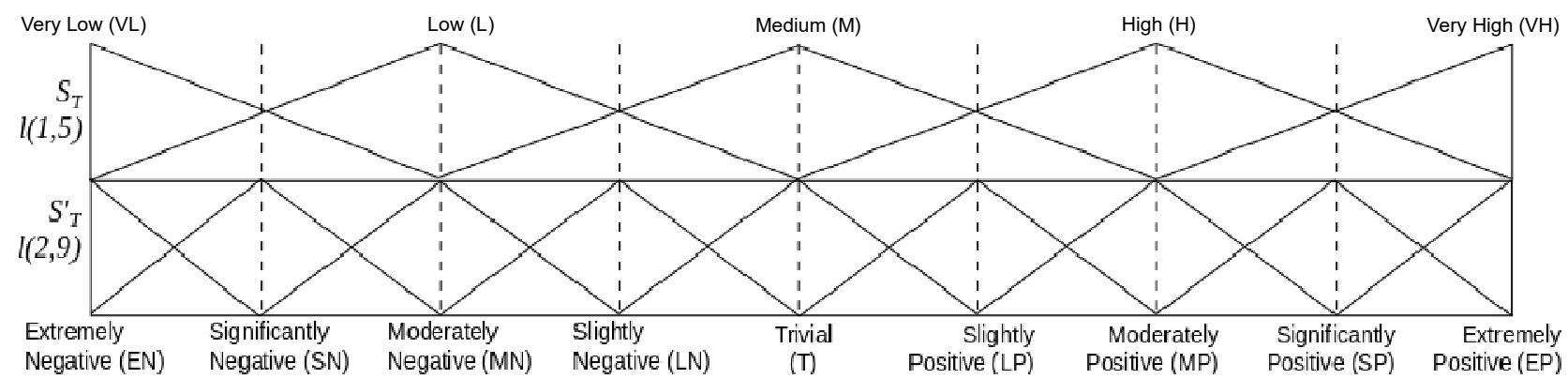

Figure 5. Linguistic set of nine terms addressing negative and positive significance values.

The weights of criteria are $\mathrm{W}=(0.3,0.3,0.1,0.15,0.15)$.

- Selection of information domains to assess criteria: The expression domains used to assess the criteria depends on the criteria nature (qualitative or quantitative). For example, the moment of an impact $c_{3}$, is assessed using numerical values on $[0,1]$, because it represents the time between the start of the action and the start of the impact. But, due to the complexity of the problem, experts might have hesitation when they express their assessments and they do not want to provide just one value, because the use of only one value cannot reflect their hesitation about their assessment. Therefore, in order to avoid missing values in the gathering preferences, we use hesitant information. In this example, we have considered that the criteria $\left\{c_{1}, c_{2}, c_{4}, c_{5}\right\}$ are assessed by using hesitant information, but it is worthy to note that the use of this type of information will depend on the experts and criteria.

\subsubsection{Gathering Preferences}

In this phase every impact is submitted to experts evaluation. The gathered heterogeneous preferences are shown in Table 1 .

\subsubsection{Rating Alternatives}

This phase of the EISA approach computes a collective significance value for each item according to the information gathered in the previous phase.

\section{Normalization}

Just point out that $c_{3}$ is a cost criterion, so it is normalized according to Equation (5), for example: $x_{11}^{31}=1-x_{11}^{31}=1-0.3$ $=0.7$.

\section{Unification into a linguistic domain}

Once all preferences are expressed in the same direction, they are unified into 2-tuple linguistic values. The first step is to select the BLTS ST, that in this case is $S_{T}=S^{5}$ which is the linguistic domain used to provide preferences. The unification is then conducted according to the information domain of data. In order to clarify the transformation of linguistic expressions into 2-tuple linguistic values, we show the transformation of the expression "greater than Low" provided by expert $e_{1}$ for impact $I_{11}$ about criterion $c_{1}$ :

$$
\tau_{H_{S} S_{T}}(\{M, H, V H\})=\Delta\left(\frac{1}{4} \Delta^{-l}(V H, 0)+\frac{1}{4} \frac{1}{2} \Delta^{-I}(H, 0)+\frac{1}{2} \Delta^{-I}(M, 0)\right)=(H,-0.25)
$$

The OWA weights were generated using the method proposed by Liu and Rodríguez (Liu and Rodríguez, 2014). Table 2 shows the unified 2-tuple linguistic values.

\section{Multi-step Aggregation Process}

Following the Conesa's method in this step, the aggregation operators, 2-tuple arithmetic mean and 2-tuple weighted mean are applied (see Appendix).

\section{(a) Computing collective criteria values:}

From linguistic assesments, the criteria collective values are then computed for each impact using Eq. (11). The results are shown in Table 3 . The collective value of the criterion $c_{1}$ for the impact $I_{11}$ is computed as follows:

$$
\left.\zeta_{11}^{1}=\Phi((H,-0.25)),(M, 0),(L, 0.25)\right)=\Delta\left(\frac{2.75+2+1.25}{3}\right)=(M, 0)
$$

\section{(b) Computing impacts' significance:}

The significance values of impacts are generated by aggregating the previous collective criteria values obtained through Eqquation (12). The results are shown in Table 4, column 2. The significance value of impact $I_{11}$ is computed as:

$$
\begin{aligned}
& \zeta_{11}=\Psi((M, 0),(M, 0.19)(H,-0.07),(M, 0.27),(M,-0.42))= \\
& \Delta(0.3 * 2+0.3 * 2.19+0.1 * 2.93+0.15 * 2.27+0.15 * 1.58)= \\
& \quad(M, 0.13)
\end{aligned}
$$

\section{(c) Adjusting significance:}

The results are represented by 2-tuple linguistic values on $S^{5}$ and they do not tell us if the impact is positive or negative, therefore, such values must be adjusted. Taking the BLTS $S_{T}=$ $S^{5}$ as level 1 of the LH, we generate the level 2 obtaining an LH whose linguistic term sets are:

$$
\begin{array}{ll}
S_{T}: l(1,5) & \left\{s_{0}^{5}, s_{1}^{5}, s_{2}^{5}, s_{3}^{5} s_{4}^{5}\right\} \\
S_{T}^{\prime}: l(2,9) & \left\{s_{0}^{9}, s_{1}^{9}, s_{2}^{9}, s_{3}^{9}, s_{4}^{9}, s_{5}^{9} s_{6}^{9} s_{7}^{9}, s_{8}^{9}\right\}
\end{array}
$$

Once the syntax of the ALTS $S^{\prime}{ }_{\mathrm{T}}=S^{9}$ is obtained, its se 
Table 1. Heterogeneous Preferences Provided by Experts.

\begin{tabular}{|c|c|c|c|c|c|}
\hline$I_{i j}$ & $c_{1}$ & $c_{2}$ & $c_{3}$ & $c_{4}$ & $c_{5}$ \\
\hline \multicolumn{6}{|l|}{$e_{1}$} \\
\hline$I_{11}$ & gr than $\mathrm{L}$ & $\{0.3,0.4,0.5\}$ & 0.3 & gr than L & bt L \& M \\
\hline$I_{12}$ & $\mathrm{H}$ & $\{0.4,0.5,0.6\}$ & 0.1 & M & bt $\mathrm{M} \& \mathrm{H}$ \\
\hline$I_{13}$ & M & $\{0.6,0.7\}$ & 0.1 & M & bt M \& H \\
\hline$I_{21}$ & bt H \& VH & $\{0.9,1.0\}$ & 0 & gr than $\mathrm{H}$ & $\mathrm{H}$ \\
\hline$I_{23}$ & gr than $\mathrm{M}$ & $\{0.3,0.4,0.5\}$ & 0 & lw than $\mathrm{M}$ & lw than $\mathrm{M}$ \\
\hline \multicolumn{6}{|l|}{$e_{2}$} \\
\hline$I_{11}$ & M & $\{0.4,0.5,0.6\}$ & 0.2 & at least $\mathrm{M}$ & M \\
\hline$I_{12}$ & at least $\mathrm{H}$ & $\{0.6,0.7,0.8\}$ & 0.2 & $\mathrm{M}$ & $\mathrm{H}$ \\
\hline$I_{13}$ & M & $\{0.5,0.6,0.7\}$ & 0.2 & M & bt $M \& H$ \\
\hline$I_{21}$ & at least $\mathrm{H}$ & $\{0.8,0.9\}$ & 0.1 & bt $\mathrm{M} \& \mathrm{H}$ & $\mathrm{H}$ \\
\hline$I_{23}$ & gr than $\mathrm{M}$ & $\{0.3,0.4,0.5\}$ & 0.3 & gr than L & gr than $\mathrm{L}$ \\
\hline \multicolumn{6}{|l|}{$e_{3}$} \\
\hline$I_{11}$ & at most $\mathrm{M}$ & $\{0.7,0.8\}$ & 0.3 & at least L & at most $\mathrm{M}$ \\
\hline$I_{12}$ & $\mathrm{H}$ & $\{0.4,0.5,0.6\}$ & 0.1 & bt $\mathrm{M} \& \mathrm{H}$ & $\mathrm{M}$ \\
\hline$I_{13}$ & M & $\{0.5,0.6,0.7\}$ & 0.1 & M & bt M \& H \\
\hline$I_{21}$ & at least $\mathrm{H}$ & $\{0.8,0.9,1.0\}$ & 0 & at most $\mathrm{H}$ & $\mathrm{H}$ \\
\hline$I_{23}$ & at most $\mathrm{H}$ & $\{0.5,0.6\}$ & 0 & $\mathrm{~L}$ & $\mathrm{~L}$ \\
\hline
\end{tabular}

Note: bt stands for between, gr stands for greater and lw stands for lower.

Table 2. Unified Preferences

\begin{tabular}{|c|c|c|c|c|c|}
\hline$I_{i j}$ & $c_{1}$ & $c_{2}$ & $c_{3}$ & $c_{4}$ & $c_{5}$ \\
\hline \multicolumn{6}{|l|}{$e_{1}$} \\
\hline$I_{11}$ & $(\mathrm{H},-0.25)$ & $(\mathrm{M},-0.44)$ & $(\mathrm{H},-0.2)$ & $(\mathrm{H},-0.25)$ & $(\mathrm{M},-0.5)$ \\
\hline$I_{12}$ & $(\mathrm{H}, 0)$ & $(\mathrm{M}, 0)$ & $(\mathrm{VH},-0.4)$ & $(\mathrm{M}, 0)$ & $(\mathrm{H},-0.5)$ \\
\hline$I_{13}$ & $(\mathrm{M}, 0)$ & $(\mathrm{H},-0.4)$ & $(\mathrm{VH},-0.4)$ & $(\mathrm{M}, 0)$ & $(\mathrm{H},-0.5)$ \\
\hline$I_{21}$ & $(\mathrm{VH},-0.5)$ & $(\mathrm{VH},-0.28)$ & $(\mathrm{VH}, 0)$ & $(\mathrm{VH}, 0)$ & $(\mathrm{H}, 0)$ \\
\hline$I_{23}$ & $(\mathrm{VH},-0.25)$ & $(\mathrm{M},-0.44)$ & $(\mathrm{VH}, 0)$ & $(\mathrm{VL}, 0.25)$ & $(\mathrm{VL}, 0.25)$ \\
\hline \multicolumn{6}{|l|}{$e_{2}$} \\
\hline$I_{11}$ & $(\mathrm{M}, 0)$ & $(\mathrm{M}, 0)$ & $(\mathrm{H}, 0.2)$ & $(\mathrm{H},-0.25)$ & $(\mathrm{M}, 0)$ \\
\hline$I_{12}$ & $(\mathrm{VH},-0.25)$ & $(\mathrm{H},-0.22)$ & $(\mathrm{H}, 0.2)$ & $(\mathrm{M}, 0)$ & $(\mathrm{H}, 0)$ \\
\hline$I_{13}$ & $(\mathrm{M}, 0)$ & $(\mathrm{M}, 0.44)$ & $(\mathrm{H}, 0.2)$ & $(\mathrm{M}, 0)$ & $(\mathrm{H},-0.5)$ \\
\hline$I_{21}$ & $(\mathrm{VH},-0.25)$ & $(\mathrm{H}, 0.42)$ & $(\mathrm{VH},-0.4)$ & $(\mathrm{H},-0.5)$ & $(\mathrm{H}, 0)$ \\
\hline$I_{23}$ & $(\mathrm{VH},-0.25)$ & $(\mathrm{M},-0.44)$ & $(\mathrm{H},-0.2)$ & $(\mathrm{H},-0.25)$ & $(\mathrm{H},-0.25)$ \\
\hline \multicolumn{6}{|l|}{$e_{3}$} \\
\hline$I_{11}$ & $(\mathrm{~L}, 0.25)$ & $(\mathrm{H}, 0)$ & $(\mathrm{H},-0.2)$ & $(\mathrm{L}, 0.32)$ & $(\mathrm{L}, 0.25)$ \\
\hline$I_{12}$ & $(\mathrm{H}, 0)$ & $(\mathrm{M}, 0)$ & $(\mathrm{VH},-0.4)$ & $(\mathrm{H},-0.5)$ & $(\mathrm{M}, 0)$ \\
\hline$I_{13}$ & $(\mathrm{M}, 0)$ & $(\mathrm{M}, 0.44)$ & $(\mathrm{VH},-0.4)$ & $(\mathrm{M}, 0)$ & $(\mathrm{H},-0.5)$ \\
\hline$I_{21}$ & $(\mathrm{VH},-0.25)$ & $(\mathrm{VH},-0.44)$ & $(\mathrm{VH}, 0)$ & $(\mathrm{H},-0.32)$ & $(\mathrm{H}, 0)$ \\
\hline$I_{23}$ & $(\mathrm{H},-0.32)$ & $(\mathrm{M},-0.28)$ & $(\mathrm{VH}, 0)$ & $(\mathrm{L}, 0)$ & $(\mathrm{L}, 0)$ \\
\hline
\end{tabular}

mantic is defined according to the significance scale proposed by (Pastakia and Jesen, 1998) (see Figure 5).

Applying Equation (14) is obtained the adjusted significance values of impacts in $S^{9}$, (see Table 4, column 3).

\section{(d) Computing final significance values:}

The significance values for factors and actions are individually computed using Equations (15) and (16). And the global significance value of the project is computed using Equation (17) (see Table 5).

\section{Ranking alternatives}

Finally, the rankings of impacts, factors and actions are obtained by using the comparison operation of 2-tuple:

- Impacts' ranking: $I_{33}>I_{11}>I_{13}>I_{12}>I_{21}$.

- Factors' ranking: $f_{3}>f_{1}>f_{2}$.

- Actions' ranking: $a_{3}>a_{2}>a_{1}$.

The linguistic value for the global significance of the project means that the overall impact caused by the implementation of the mining project in "El Cacao" deposit is Moderately Negative. 
Table 3. Collective Criteria Values.

\begin{tabular}{llllll}
\hline$I_{i j}$ & $c_{1}$ & $c_{2}$ & $c_{3}$ & $c_{4}$ & $c_{5}$ \\
\hline$I_{11}$ & $(\mathrm{M}, 0)$ & $(\mathrm{M}, 0.19)$ & $(\mathrm{H},-0.07)$ & $(\mathrm{M}, 0.27)$ & $(\mathrm{M},-0.42)$ \\
$I_{12}$ & $(\mathrm{H}, 0.25)$ & $(\mathrm{M}, 0.26)$ & $(\mathrm{H}, 0.47)$ & $(\mathrm{M}, 0.17)$ & $(\mathrm{H},-0.50)$ \\
$I_{13}$ & $(\mathrm{M}, 0)$ & $(\mathrm{M}, 0.49)$ & $(\mathrm{H}, 0.47)$ & $(\mathrm{M}, 0)$ & $(\mathrm{H},-0.50)$ \\
$I_{21}$ & $(\mathrm{VH},-0.33)$ & $(\mathrm{VH},-0.43)$ & $(\mathrm{VH},-0.13)$ & $(\mathrm{H}, 0.06)$ & $(\mathrm{H}, 0)$ \\
$I_{23}$ & $(\mathrm{H}, 0.39)$ & $(\mathrm{M},-0.39)$ & $(\mathrm{VH},-0.40)$ & $(\mathrm{L}, 0.33)$ & $(\mathrm{L}, 0.33)$ \\
\hline
\end{tabular}

Table 4. Significance Values for Impacts

\begin{tabular}{lll}
\hline$I_{i j}$ & $\begin{array}{l}\zeta_{i j} \text { Non adjusted } \\
\text { significance values }\end{array}$ & $\begin{array}{l}\zeta_{i j}^{\prime} \text { Adjusted } \\
\text { significance values }\end{array}$ \\
\hline$I_{11}$ & $(\mathrm{M}, 0.13)$ & $(\mathrm{MN},-0.13)$ \\
$I_{12}$ & $(\mathrm{H},-0.30)$ & $(\mathrm{SN}, 0.30)$ \\
$I_{13}$ & $(\mathrm{M}, 0.37)$ & $\mathrm{MN},-0.37)$ \\
$I_{21}$ & $(\mathrm{H}, 0.47)$ & $(\mathrm{SN},-0.47)$ \\
$I_{23}$ & $(\mathrm{M}, 0.26)$ & $(\mathrm{MP}, 0.26)$ \\
\hline
\end{tabular}

Table 5. Significance Values for Factors, Actions and the Project

\begin{tabular}{llll}
\hline & $f_{1}$ & $f_{2}$ & $f_{3}$ \\
\hline$\zeta_{i}^{F}$ & $(\mathrm{MN},-0.4)$ & $(\mathrm{MN},-0.4)$ & $(\mathrm{MN},-0.4)$ \\
& $a_{1}$ & $a_{2}$ & $a_{3}$ \\
$\zeta_{j}^{A}$ & $(\mathrm{SN}, 0.2)$ & $(\mathrm{SN}, 0.2)$ & $(\mathrm{SN}, 0.2)$ \\
& project & project & project \\
$\zeta$ & $(\mathrm{MN}, 0.33)$ & $(\mathrm{MN}, 0.33)$ & $(\mathrm{MN}, 0.33)$ \\
\hline
\end{tabular}

Table 6. Comparison of Approaches

\begin{tabular}{|c|c|c|}
\hline & Crisp matrix & $\begin{array}{l}\text { Hesitant heterogeneous } \\
\text { EISA }\end{array}$ \\
\hline $\begin{array}{l}\text { Uncertainty } \\
\text { modeling }\end{array}$ & No & Yes \\
\hline $\begin{array}{l}\text { Expression } \\
\text { domains }\end{array}$ & $\begin{array}{l}\text { Fixed } \\
\text { numerical scales }\end{array}$ & $\begin{array}{l}\text { Numerical, linguistic, } \\
\text { interval values, HFS } \\
\text { and HFLTS }\end{array}$ \\
\hline Results & Numeric & $\begin{array}{l}\text { Linguistic expressed } \\
\text { into 2-tuple }\end{array}$ \\
\hline Interpretability & $\begin{array}{l}\text { Low, due to it is diffi- } \\
\text { cult to represent quali- } \\
\text { tative subjects through } \\
\text { precise numeric values }\end{array}$ & $\begin{array}{l}\text { High, due to there is an } \\
\text { unique bipolar linguis- } \\
\text { tic scale which synthe- } \\
\text { sizes understandable } \\
\text { significance of impacts }\end{array}$ \\
\hline $\begin{array}{l}\text { Impact } \\
\text { significance calculation }\end{array}$ & Fixed formula & $\begin{array}{l}\text { Aggregation using } \\
\text { 2-tuple operators, de- } \\
\text { pending on problem } \\
\text { features and require- } \\
\text { ments of decision mak- } \\
\text { ers }\end{array}$ \\
\hline
\end{tabular}

\section{Advantages of the Proposed Approach}

As mentioned in Section 2, the classical crisp matrix for EISA has some disadvantages that we have attempted to overcome with the new hesitant heterogeneous EISA approach. It not only preserves the traditional use of numerical values, but also improves the evaluation framework, including other information domains to assess the criteria according to their nature and improve the uncertainties modeling and data representation in EISA.

Additionally, the use of hesitant information allows experts to be comfortable when they provide their opinions and hesitate about them, because they can use hesitant information to reflect their hesitation in a flexible way.

Another important feature of this proposal is the use of the 2-tuple linguistic model to represent both the heterogeneous and the hesitant information, and to carry out the CWW processes. This allows to apply different 2-tuple aggregation operators, according to the specific problem and the requirements of decision makers. It also obtains linguistic results in each step, which are easier to understand by human beings than numerical values.

Table 6 summarizes a comparison of the EISA approaches addressed in this paper.

\section{Conclusions}

EISA problems consider multiple criteria whose nature can be quantitative or qualitative. However, classical approaches for EISA do not manage heterogeneous information efficiently and the results are numerical values difficult to interpret by stakeholders. Therefore, in this paper a new approach for EISA has been proposed, which deals with hesitant heterogeneous information including not only numerical, interval-valued and linguistic domains, but also hesitant information which allows to model the hesitancy and uncertainty in qualitative and quantitative contexts. This approach conducts heterogeneous assessments to 2-tuple linguistic values in order to accomplish the processes of CWW and to obtain easy-to-understand linguistic results. The approach also enables calculating the significance values for impacts that are aggregated to obtain significance values for actions and factors, as well as a global significance value for the project impact. An illustrative example about the limestone mining in "El Cacao" has been presented to show the performance of the proposed approach.

Acknowledgments: This contribution has been supported by the research project TIN2012-31263, Spanish Ministry of Economy and Finance Postdoctoral Training (FPDI-2013-18193) and ERDF.

\section{Appendix}

This appendix revises some basic and necessary concepts 
to understand the proposed approach for EISA. It reviews the 2-tuple linguistic model, its computational model and some of its extensions, such as the heterogeneous approach to deal with different types of information and the multigranular model which manages different linguistic scales.

\section{2-Tuple Linguistic Model}

The 2-tuple linguistic model was proposed by Herrera and Martínez to improve the accuracy of the computing with words (CWW) processes and avoid the loss of information (Herrera and Martínez, 2000; Rodríguez and Martínez, 2013) keeping the linguistic basis (semantics and syntax). This model represents the linguistic information by means of a pair of values called 2-tuple $\left(s_{i}, \alpha\right) \in \bar{S}=S \times[-0.5,0.5)$, where $s_{i} \in S$ is a linguistic term and $\alpha \in[-0.5,0.5)$ is a numerical value that represents the symbolic translation.

Definition 8 (Herrera and Martínez, 2000): The symbolic translation is a numerical value assessed in $[-0.5,0.5)$ that supports the "difference of information" between a counting of information assessed in the interval of granularity $[0, g]$ of the linguistic term set $S$, and the closest value in $\{0, \ldots, g\}$ which indicates the index of the closest linguistic term in $S$.

This representation model defines the functions $\Delta$ and $\Delta^{-1}$ to facilitate the CWW processes (Herrera and Martínez, 2000).

Definition 9 (Martínez and Herrera, 2012) Let $S=\left\{s_{0}, \ldots\right.$, $s g\}$ be a set of linguistic terms and $\beta \in[0, g]$ a value supporting the result of a symbolic aggregation operation. A 2-tuple linguistic value that expresses the equivalent information to $\beta$ is obtained as follows:

$\Delta:[0, g] \rightarrow \bar{S}$

$\Delta(\beta)=\left(s_{i}, \alpha\right)$, with $\left\{\begin{array}{l}i=\operatorname{round}(\beta), \\ \alpha=\beta-i,\end{array}\right.$

being round the round operation, $i$ the index of the closest label $s_{i}$, to $\beta$ and $\alpha$ the symbolic translation.

We note that $\Delta$ is a bijective function and $\Delta^{-1}: \bar{S} \rightarrow[0, g]$ is defined by $\Delta^{-1}\left(s_{i}, \alpha\right)=i+a$.

The 2-tuple linguistic model defined a computational model based on the functions $\Delta$ and $\Delta^{-1}$ and introduced the comparison between two 2-tuples linguistic values and several aggregation operators (Herrera and Martínez, 2000).

Let us suppose two 2-tuple linguistic values, $\left(s_{k}, \alpha_{1}\right)$ and $\left(s_{l}, \alpha_{2}\right)$, the comparison is as follows:

- if $k<l$ then $\left(s_{k}, \alpha_{1}\right)<\left(s_{l}, \alpha_{2}\right)$.

- if $k=l$ then

$\circ$ if $\alpha_{1}=\alpha_{2}$ then $\left(s_{k}, \alpha_{1}\right)=\left(s_{l}, \alpha_{2}\right)$;

$\circ$ if $\alpha_{1}<\alpha_{2}$ then $\left(s k, \alpha_{1}\right)<\left(s l, \alpha_{2}\right)$;

$\circ$ if $\alpha_{1}>\alpha_{2}$ then $\left(s_{k}, \alpha_{1}\right)>\left(s, \alpha_{2}\right)$.

In the literature can be found different aggregation operators defined for 2-tuple linguistic values (Herrera and Martínez, 2000; Liu et al., 2013; Merigó et al., 2010; Wan, 2013). We only revise the arithmetic mean and the weighted mean because they are used in the illustrative example shown in Section 5.

Definition 10 (Herrera and Martínez, 2000): Let $x=\left\{\left(s_{1}\right.\right.$, $\left.\left.\alpha_{1}\right), \ldots,\left(s_{m}, \alpha_{m}\right)\right\}$ be a set of 2-tuple linguistic values, the 2-tuple arithmetic mean is the function $\Phi: \bar{S}^{m} \rightarrow \bar{S}$ defined as:

$\Phi(x)=\Delta\left(\frac{1}{n} \sum_{i=1}^{m} \Delta^{-1}\left(s_{i}, \alpha_{i}\right)\right)$

Definition 11 (Herrera and Martínez, 2000): Let $x=\left\{\left(s_{1}\right.\right.$, $\left.\left.\alpha_{1}\right), \ldots,\left(s_{m}, \alpha_{m}\right)\right\}$ be a set of 2-tuple linguistic values, and $\mathrm{W}=$ $\left(w_{1}, \ldots, w_{m}\right), w_{i} \in[0.1]$ be a weighting vector such that $\sum_{i=1}^{m} w_{i}$ $=1$, the 2-tuple weighted mean operator associated with $\underset{W}{W}$ is the function $\Phi: \bar{S}^{m} \rightarrow \bar{S}$ defined as:

$\psi(x)=\Delta\left(\frac{\sum_{i=1}^{m} w_{i}^{*} \Delta^{-1}\left(s_{i}, \alpha_{i}\right)}{\sum_{i=1}^{m} w_{i}}\right)$

\section{2-Tuple Based Model to Deal with Heterogeneous Informa-} tion

Usually, in problems with multiple criteria and/or experts is common the appearance of different types of information that might be modeled with heterogenous information such as numerical, interval-valued, linguistic and forth. For this type of framework was introduced in (Herrera et al., 2005) a 2-tuple based model to manage and operate with this type of information. It conducts the heterogeneous information into 2-tuple linguistic values to facilitate the computations and obtain results easy to understand for experts involved in the problem. It consists of three steps.

1. Choosing the Basic Linguistic Term Set (BLTS): The selected BLTS, $S_{T}=\left\{s_{0}, \ldots, S_{g}\right\}$, must have the maximum granularity to maintain the uncertainty degree associated to each expert, as well as the ability of discrimination to express the preference values. To achieve both purposes some suggestions are detailed in (Herrera et al., 2005).

2. Transforming into fuzzy sets: Each value is then transformed into a fuzzy set on $S_{T}, F\left(S_{T}\right)$, using one of the following functions:

(a) Numerical domain

Definition 12 (Herrera et al., 2005) Let $\vartheta \in[0,1]$ be a numerical value and $S_{T}=\left\{s_{0}, \ldots, s_{g}\right\}$ be a linguistic term set. The transformation function $\tau_{N S_{T}}:[0,1] \rightarrow F\left(S_{T}\right)$ defined by $\tau_{N S_{T}}(\vartheta)=\sum_{i=0}^{g} s_{i} / \gamma_{i}$ transforms a numerical value into a fuzzy set in $S_{T}$ :

$$
\gamma_{i}=\mu_{s_{i}}(\vartheta)= \begin{cases}0, & \vartheta<a \text { or } \vartheta>c, \\ (\vartheta-a) /(b-a), & a<\vartheta<b, \\ 1, & b \leq \vartheta \leq d, \\ (c-\vartheta) /(c-d), & d<\vartheta<c,\end{cases}
$$

being $F\left(S_{T}\right)$ the set of fuzzy sets on $S_{T}, \quad \gamma_{i}=\mu_{s_{i}}(\vartheta) \in[0,1]$ the 
membership degree of $\vartheta$ to $s_{i} \in S_{T}$, and $(a, b, d, c)$ a parametric membership function.

\section{(b) Interval domain}

Definition 13 (Herrera et al., 2005) Let $V=[\bar{a}, \underline{a}]$ be an interval in $[0,1]$, the transformation function $\tau_{V S_{T}}: V \rightarrow F\left(S_{T}\right)$ defined by $\tau_{V S_{T}}(V)=\sum_{i=0}^{g} s_{i} / \gamma_{i}$ transforms an interval $V$ into a fuzzy set $S_{T}$ :

$\gamma_{i}=\operatorname{maxmin}_{y}\left\{\mu_{V}(y), \mu_{s_{i}}(y)\right\}, i=\{0, \ldots, g\}$

where $F\left(S_{T}\right)$ is the set of fuzzy sets on $S_{T}$, and $\mu_{V}$ and $\mu_{s_{i}}$ the membership functions of the fuzzy sets associated to the interval $V$ and the terms $s_{i} \in S_{T}$, respectively.

\section{(c) Linguistic domain}

Definition 14 (Herrera et al., 2005) Let $S_{T}=\left\{s_{0}, \ldots, s_{g}\right\}$ be a linguistic term set, the transformation function $\tau_{S S_{T}}: \mathrm{S} \rightarrow$ $F\left(S_{T}\right)$ defined by $\tau_{S S_{T}}\left(s_{j}\right)=\sum_{i=0}^{g} s_{i} / \gamma_{i}$ transforms a linguistic term into a fuzzy set in $S_{T}$ :

$\gamma_{i}=\operatorname{maxmin}_{y}\left\{\mu_{s_{j}}(y), \mu_{s_{i}}(y)\right\}, i=\{0, \ldots, g\}$

being $F\left(S_{T}\right)$ the set of fuzzy sets on $S_{T}, \mu_{s_{i}}$ and $\mu_{s_{i}}$ the membership functions of the fuzzy sets associated to the terms $s_{j} \in S$ and $s_{i} \in S_{T}$ respectively.

3. Transforming into linguistic 2-tuple values: Finally the fuzzy sets are transformed into linguistic 2-tuple values over the BLTS, using the function $\chi(\cdot)$.

Definition 15 (Martínez and Herrera, 2012) Let $F\left(S_{T}\right)$ be a fuzzy set in $S_{T}$, the function $\chi: F\left(S_{T}\right) \rightarrow \bar{S}$ is defined as:

$\chi\left(F\left(S_{T}\right)\right)=\Delta\left(\sum_{j=0}^{g} j \gamma_{j} / \sum_{j=0}^{g} \gamma_{j}\right)=\Delta(\beta)=\left(s_{l}, \alpha\right)$

where the fuzzy set $\mathrm{F}\left(\mathrm{S}_{\mathrm{T}}\right)$ can be obtained from $\tau_{N S_{T}}, \tau_{V S_{T}}$ or $\tau_{S S_{T}}$, respectively.

\section{2-Tuple Based Model to Manage Multigranular Linguistic Information. Linguistic Hierarchies}

Sometimes, it is necessary to deal with linguistic frameworks in which the linguistic information can belong to linguistic term sets with different granularity. In (Herrera and Martínez, 2001) was presented an approach to manage multigranular linguistic information in a symbolic and precise way by means of Linguistic Hierarchies (LH). This approach builds a structure so-called linguistic hierarchy, and a computational symbolic model based on the 2-tuple linguistic model is defined over it to accomplish the CWW processes.

A LH is the union of all levels $t: L H=\cup_{t} l(t, n(t))$, where each level $t$ of a LH corresponds to a linguistic term set with a granularity of uncertainty of $n(t)$ denoted as: $S^{n(t)}=\left\{s_{0}^{n(t)}\right.$, $\left.\ldots, s_{n(t)-1}^{n(t)}\right\} \quad$ (Herrera and Martínez, 2001).

The construction of LH must satisfy a pair of rules, so-ca- lled linguistic hierarchy basic rules (Herrera and Martínez, 2001):

- To preserve all former modal points of the membership functions of each linguistic term from one level to the following one.

- To make smooth transitions between consecutive levels.

The goal is to add a new linguistic term set $S^{n(t+1)}$ by adding a new linguistic term between each pair of terms belonging to the linguistic term set of the previous level $t$. To do so, it is necessary to reduce the support of the linguistic labels to keep place for the new one located in the middle of them. Therefore, a linguistic term set in the level $t+1$ is obtained from its predecessor as $l(t, n(t)) \rightarrow l(t+1,2 * n(t)-1)$. Figure 5 shows a $\mathrm{LH}$ according to the rules mentioned.

A transformation function was defined to transform a linguistic term in level $t$ to its correspondent linguistic term in level $t+1$ following the linguistic hierarchy basic rules (Herrera and Martínez, 2001).

\section{References}

Ahmadi, A., Moridi, A., and Han, D. (2015). Uncertainty assessment in environmental risk through Bayesian networks. J. Environ. Inf., 25(1), 46-59. https://doi.org/10.3808/jei.201500294

Bojórquez-Tapia, L.A., Ezcurra, E., and García, O. (1998). Appraisal of environmental impacts and mitigation measures through mathematical matrices. J. Environ. Manage., 53(1), 91-99. https://doi. org/10.1006/jema.1998.0191

Bojórquez-Tapia, L.A., Sánchez, S., and Florez, A. (2005). Building consensus in environmental impact assessment through multicriteria modeling and sensitivity analysis. Environ. Manage., 36(3), 469481. https://doi.org/10.1007/s00267-004-0127-5

Carrasco, R.A., and Villar, P. (2012). A new model for linguistic summarization of heterogeneous data: an application to tourism web data sources. Soft Comput., 16(1), 135-151. https://doi.org/10. 1007/s00500-011-0740-1

Clemen, R.T. (1996). Making Hard Decisions: An Introduction to Decision Analysis, Duxbury Press, Boston.

Cloquell-Ballester, V.A., Monterde-Díaz, R., Cloquell-Ballester, V.A., and Santamarina-Siurana, M.C. (2007). Systematic comparative and sensitivity analyses of additive and outranking techniques for supporting impact significance assessments. Environ. Impact Assess. Rev., 27(1), 62-83. https://doi.org/10.1016/j.eiar.2006.08.005

Conesa Fernandez-Vitora, V. (1997). Guía metodológica para la evaluación del impacto ambiental. Mundi-Prensa, Madrid.

Dee, N., Baker, J., Drobny, N., Whitman, I., Duke, K., and Fahringer, D. (1973). An environmental evaluation system for water resource planning. Water Resour. Res., 9(3), 523-535. https://doi.org/10.10 29/WR009i003p00523

Hernández-Jatib, N., Ulloa-Carcasés, M., and Rosario, Y. (2011). Impacto ambiental de la explotación del yacimiento de materiales de construcción El Cacao. Minería y Geología, 27(1), 38-53

Herrera, F., Martínez, L., and Sánchez, P.J. (2005). Managing non-homogeneous information in group decision making. Eur. J. Oper. Res., 166(1), 115-132. https://doi.org/10.1016/j.ejor.2003.11. 031

Herrera, F., and Martínez, L. (2000). A 2-tuple fuzzy linguistic representation model for computing with words. IEEE Trans. Fuzzy Syst., 8(6), 746-752. https://doi.org/10.1109/91.890332

Herrera, F., and Martínez, L. (2001). A model based on linguistic 2-tuples for dealing with multigranular hierarchical linguistic con- 
texts in multi-expert decision-making. IEEE Trans. Syst. Man Cybern. B, 31(2), 227-234. https://doi.org/10.1109/3477.915345

Ijas, A., Kuitunen, M.T., and Jalava, K. (2010). Developing the RIAM method (Rapid Impact Assessment Matrix) in the context of impact significance assessment. Environ. Impact Assess. Rev., 30(2), 82-89. https://doi.org/10.1016/j.eiar.2009.05.009

Ishizaka, A., and Nemery, P. (2013). Multi-criteria Decision Analysis: Methods and Software, John Wiley \& Sons, Inc. https://doi.org/10. $1002 / 9781118644898$

Krueger, T., Page, T., Hubacek, K., Smith, L., and Hiscock, K. (2012). The role of expert opinion in environmental modelling. Environmental Modelling \& Software, 36, 4-18. https://doi.org/10.1016/j. envsoft.2012.01.011

Lawrence, D.P. (2013). Environmental Impact Assessment. Practical Solutions to Recurrent Problems and Contemporary Challenges, John Wiley \& Sons, New Jersey.

Li, D.F., Huang, Z.G., and Chen, G.H. (2010). A systematic approach to heterogeneous multiattribute group decision making. Comput Ind. Engi., 59(4), 561-572. https://doi.org/10.1016/j.cie.2010.06.015

Li, Y.P., Huang, G.H., and Sun, W. (2011). Management of uncertain information for environmental systems using a multistage fuzzystochastic programming model with soft constraints. J. Environ. Inf., 18(1), 28-37. https://doi.org/10.3808/jei.201100196

Liao, H.C., and Xu, Z.S. (2013). A VIKOR-based method for hesitant fuzzy multi-criteria decision making. Fuzzy Optimiz. Decis. Making, 12(4), 373-392. https://doi.org/10.1007/s10700-013-9162-0

Liu, H., Cai, J., and Martínez, L. (2013). The importance weighted continuous generalized ordered weighted averaging operator and its application to group decision making. Knowledge-based Syst., 48(1), 24-36. https://doi.org/10.1016/j.knosys.2013.04.002

Liu, H., and Rodríguez, R.M. (2014). A fuzzy envelope for hesitant fuzzy linguistic term set and its application to multicriteria decision making. Inf. Sci., 258, 220-238. https://doi.org/10.1016/j.ins.2013. 07.027

Martínez, L., and Herrera, F. (2012). An overview on the 2-tuple linguistic model for computing with words in decision making: Extensions, applications and challenges. Inf. Sci., 207(1), 1-18. https://doi.org/10.1016/j.ins.2012.04.025

Martínez, L., Ruan, D., and Herrera, F. (2010). Computing with words in decision support systems: An overview on models and applications. Int. J. Comput. Intell. Syst., 3(4), 382-395. https://doi. org/10.1080/18756891.2010.9727709

Merigó, J.M., Casanovas, M., and Martínez, L. (2010). Linguistic aggregation operators for linguistic decision making based on the dempster-shafer theory of evidence. Int. J. Unc. Fuzz. Knowl. Based Syst., 18(03), 287-304. https://doi.org/10.1142/S021848851 0006544

Morón, A.B., Calvo-Flores, M.D., Ramos, J.M.M., and Almohano, M.P.P. (2009). AIEIA: Software for fuzzy environmental impact assessment. Expert Syst. Appl., 36(5), 9135-9149. https://doi.org/ 10.1016/j.eswa.2008.12.055

Onar, S.C., Oztaysi, B., and Kahraman, C. (2014). Strategic decision selection using hesitant fuzzy TOPSIS and interval type-2 fuzzy AHP: A case Study. Int. J. Comput. Intell. Syst., 7(5), 1002-1021. https://doi.org/10.1080/18756891.2014.964011

Pastakia, C.M.R., and Jensen, A. (1998). The rapid impact assessment matrix (RIAM) for EIA. Environ. Impact Assess. Rev., 18(5),
461-482. https://doi.org/10.1016/S0195-9255(98)00018-3

Pedrycz, W., Ekel, P., and Parreiras, R. (2011). .Models and Algorithms of Fuzzy Multicriteria Decision-Making and Their Applications, Wiley, Chichester, West Sussex, U.K.

Pei, Z., and Yi, L. (2015). A note on operations of hesitant fuzzy sets. Int. J. Comput. Intell. Syst., 8(2), 226-239. https://doi.org/10.108 0/18756891.2015.1001947

Rodríguez, R.M., and Martínez, L. (2013). An analysis of symbolic linguistic computing models in decision making. Int. J. Gen. Syst., 42 (1), 121-136. https://doi.org/10.1080/03081079.2012.710442

Rodríguez, R.M., Martínez, L., and Herrera, F. (2012). Hesitant fuzzy linguistic term sets for decision making. IEEE Trans. Fuzzy Syst., 20(1), 109-119. https://doi.org/10.1109/TFUZZ.2011.2170076

Rodríguez, R.M., Martínez, L., and Herrera, F. (2013). A group decision making model dealing with comparative linguistic expressions based on hesitant fuzzy linguistic term sets. Inf. Sci., 241(1), 28-42. https://doi.org/10.1016/j.ins.2013.04.006

Shepard, R.B. (2005). Quantifying Environmental Impact Assessments Using Fuzzy Logic, Springer Series on Environmental Management. Springer. https://doi.org/10.1007/0-387-28098-7

Toro, J., Requena, I., Duarte, O., and Zamorano, M. (2013). A qualitative method proposal to improve environmental impact assessment. Environ. Impact Assess. Rev., 43(0), 9-20. https://doi.org/10. 1016/j.eiar.2013.04.004

Torra, V. (2010). Hesitant fuzzy sets. Int. J. Intell. Syst., 25(6), 529-539. https://doi.org/10.1002/int.20418

Triantaphyllou, E. (2000). Multi-Criteria Decision Making Methods: A Comparative Study, Applied Optimization, Springer. https://doi. org/10.1007/978-1-4757-3157-6

Vrana, I., and Aly, S. (2011). Modeling heterogeneous experts' preference ratings for environmental impact assessment through a fuzzy decision making system. Environmental Software Systems, Frameworks of eEnvironment, volume 359 of IFIP Advances in Information and Communication Technology, Springer Berlin Heidelberg, pp. 535-549. https://doi.org/10.1007/978-3-642-22285$6 \_58$

Wan, S.P. (2013). Some hybrid geometric aggregation operators with 2-tuple linguistic information and their applications to multi-attribute group decision making. Int. J. Comput. Intell. Syst., 6(4), 750763. https://doi.org/10.1080/18756891.2013.804144

Wei, C., Ren, Z., and Rodríguez, R.M. (2015). A hesitant fuzzy linguistic TODIM method based on a score function. Int. J. Comput. Intell. Syst., 8(4), 701-712. https://doi.org/10.1080/18756891.2015. 1046329

Yu, D., Zhang, W., and Xu, Y. (2013). Group decision making under hesitant fuzzy environment with application to personnel evaluation. Knowledge-Based Syst., 52, 1-10. https://doi.org/10.1016/j. knosys.2013.04.010

Zadeh, L.A. (1975). The concept of a linguistic variable and its application to approximate reasoning. Inf. Sci., Part I, II, III, $(8,9)$, 199-249, 301-357, 43-80. https://doi.org/10.1016/0020-0255(75)9 0036-5

Zhang, X.L., and Xu, Z.S. (2015). Hesitant fuzzy agglomerative hierarchical clustering algorithms. Int. J. Syst. Sci., 46(3), 562-576. https://doi.org/10.1080/00207721.2013.797037 